\title{
液相噴流中で生じる化学反応の反応速度に関する実験的研究*
}

\author{
渡邊 智昭 ${ }^{* 1, * 2}$, 酒井 康彦*3, 長田 孝二*1, 寺島 修*1
}

\section{Experimental Study on a Reaction Rate in a Reactive Liquid Jet}

\author{
Tomoaki WATANABE ${ }^{* 1, * 2}$, Yasuhiko SAKAI, Kouji NAGATA and Osamu TERASHIMA \\ ${ }^{* 1}$ Department of Mechanical Science and Engineering, Nagoya University \\ Furo-cho, Chikusa-ku, Nagoya, Aichi, 464-8603 Japan \\ ${ }^{* 2}$ Research Fellow of Japan Society for the Promotion of Science
}

\begin{abstract}
A reaction rate in a planar liquid jet with a second-order chemical reaction $\mathrm{A}+\mathrm{B} \rightarrow \mathrm{R}$ is experimentally investigated. The jet flow contains the reactant $\mathrm{A}$ and the ambient flow contains the reactant $\mathrm{B}$. The concentrations of reactive species are simultaneously measured by using the optical fiber probe based on the light absorption spectrometric method. The measurement result of mean reaction rate shows that the chemical reaction mainly occurs near the jet centerline in the upstream region, and the mean reaction rate is small in the downstream region. In the upstream region, lateral profiles of concentration correlation of reactants A and B have two local minimum values located away from the jet centerline, whereas the local minimum value of concentration correlation in the downstream region is located on the jet centerline. Comparison of concentration correlation of species A and B between the reactive and non-reactive cases shows that the chemical reaction makes the concentration correlation large near the edge of jet in the upstream region, whereas the opposite effect of chemical reaction on the concentration correlation can be seen in the other region. The concentration correlation of reactants A and B are estimated by using the Toor's hypothesis or the 3E model. The results show that the concentration correlation of reactants A and B estimated by using the Toor's hypothesis is smaller in magnitude than the experimental values, and the $3 \mathrm{E}$ model also fails to accurately estimate the concentration correlation.
\end{abstract}

Key Words : Turbulent Flow, Chemical Reaction, Jet, Turbulent Mixing, Concentration Correlation

\section{1. 緒言}

乱流により複数の化学物質が混合し化学反応が進行する現象は, 燃焼器や化学反応器などの工業装置内や, 污 染物質の環境中への拡散などの樣々な分野でみられる .こうした工業装置の効率改善や化学反応を伴う流れ場の 数値計算手法の開発のために, 乱流中で生じる化学反応現象の詳細な解析が望まれている.

乱流中の化学反応を特徵づける重要な物理量の一つとして化学反応速度が挙げられる. 二次の化学反応 $\mathrm{A}+\mathrm{B} \rightarrow \mathrm{R}$ に対して, 瞬時反応速度 $W$ (ここでは反応による生成物質濃度の時間変化率を考える) は反応速度定数 $k$ と反応物 質の瞬時濃度 $\Gamma_{\mathrm{A}}, \Gamma_{\mathrm{B}}$ を用いて以下のように表される。

$$
W=k \Gamma_{\mathrm{A}} \Gamma_{\mathrm{B}}
$$

流れ場・物質拡散場を予測する手法の一つとして Reynolds 平均した流れ場・スカラー量の支配方程式を解く手法 (RANS) がある .この手法を化学反応を伴う流れ場に適用した場合，反応速度の平均值 $\langle W\rangle$ をデル化する必要 がある.ここで， $\langle *\rangle$ はアンサンブル平均を表す . 物質 $\alpha$ の濃度変動を $\gamma_{\alpha} \equiv \Gamma_{\alpha}-\left\langle\Gamma_{\alpha}\right\rangle$ と定義すると， $\langle W\rangle$ を以下

\footnotetext{
* 原稿受付 2013 年 6 月 27 日

*1 正員, 名古屋大学大学院工学研究科( $7464-8603$ 愛知県名古屋市千種区不老町)

${ }^{*} 2$ 日本学術振興会特別研究員 DC1

*3 正員, フェロー, 名古屋大学大学院工学研究科

E-mail: watanabe.tomoaki@c.nagoya-u.jp
} 


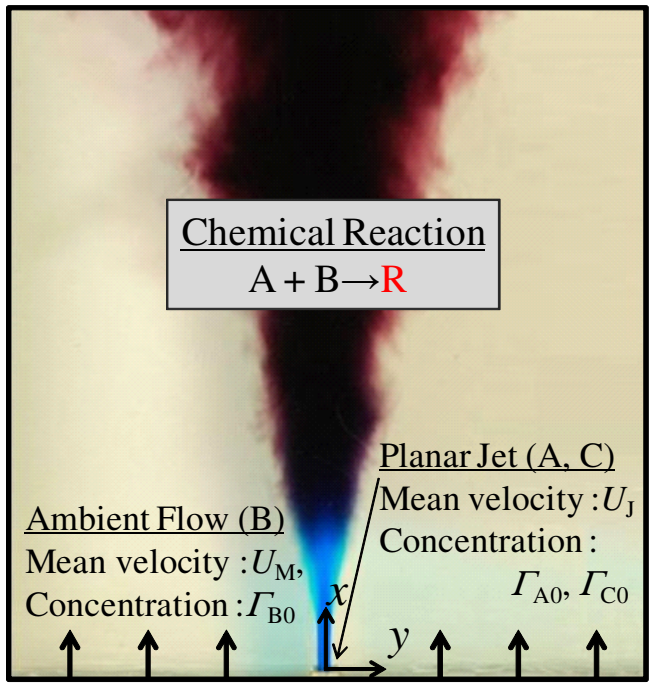

Fig. 1 Schematic diagram of the reactive planar jet.

のように平均濃度積 (右辺第一項) と濃度相関項 (右辺第二項) で表すことができる．

$$
\langle W\rangle=k\left\langle\Gamma_{\mathrm{A}}\right\rangle\left\langle\Gamma_{\mathrm{B}}\right\rangle+k\left\langle\gamma_{\mathrm{A}} \gamma_{\mathrm{B}}\right\rangle
$$

RANS により化学反応を伴う流れ場を計算する場合， $\left\langle\gamma_{\mathrm{A}} \gamma_{\mathrm{B}}\right\rangle$ をモデル化することで平均反応速度を求める. $\left\langle\gamma_{\mathrm{A}} \gamma_{\mathrm{B}}\right\rangle$ は化学反応速度や流れ場によって大きく変化する . 弚のため, $\left\langle\gamma_{\mathrm{A}} \gamma_{\mathrm{B}}\right\rangle$ のモデルの開発や，既存のモデルの評価の ためには，樣々な化学反応や流れ場に対して $\left\langle\gamma_{\mathrm{A}} \gamma_{\mathrm{B}}\right\rangle$ を計測することか望まれる . 反応速度や $\left\langle\gamma_{\mathrm{A}} \gamma_{\mathrm{B}}\right\rangle$ の計測には二 つの反応物質濃度の同時計測が必要となる . 化学反応を伴う流れ場での二つの反応物質濃度の同時計測は, 気相 のスカラー混合層 ${ }^{(1)}$, 気相の格子乱流の背後に形成される点源プルーム ${ }^{(2)}$, 液相のスカラー混合層 ${ }^{(3)}$, 液相の拘束 噴流 ${ }^{(4)(5)}$ などで行われている. また, DNS を用いて $\left\langle\gamma_{\mathrm{A}} \gamma_{\mathrm{B}}\right\rangle$ を算出した研究例 ${ }^{(6)(7)}$ もあるが, DNS ではシュミット 数 $S c=v / D$ ( $v$ : 動粘性係数, $D:$ 分子拡散係数 $)$ が大きい液相で生じる化学反応を扱うことは難しい．本研究では， シュミット数が気相と比べて大きい $(S c \approx 600)$ 液相二次元噴流中で生じる二次の化学反応 $\mathrm{A}+\mathrm{B} \rightarrow \mathrm{R}$ を対象とし て実験を行った . 化学反応を伴う液相二次元噴流中で反応に関わるすべての物質の濃度を同時計測し，平均反応 速度や濃度相関項 $\left\langle\gamma_{\mathrm{A}} \gamma_{\mathrm{B}}\right\rangle$ につて調査した . また , 反応物質の濃度相関 $\left\langle\gamma_{\mathrm{A}} \gamma_{\mathrm{B}}\right\rangle$ に対して化学反応が与える影響に ついても詳細に調査した .さらに， $\left\langle\gamma_{\mathrm{A}} \gamma_{\mathrm{B}}\right\rangle$ に対して過去に提案されたモデルによる予測值を実験值と比較し，モ デルの有効性について評価した .

主な 記 号

$\begin{array}{cc}\Gamma_{\alpha} & : \\ \gamma_{\alpha} & : \\ \xi & : \\ \xi^{\prime} & : \\ W & : \\ I_{\mathrm{S}} & : \\ k & : \\ \xi_{\mathrm{S}} & : \\ D a & :\end{array}$

上付き添え字 0 上付き添え字 $\infty$

$$
\begin{gathered}
\text { 物質 } \alpha \text { の瞬時濃度 } \\
\text { 物質 } \alpha \text { 濃度変動 } \\
\text { 混合分率の瞬時値 } \\
\text { 混合分率の変動 } \\
\text { 反応速度 } \\
\text { 混合度 }
\end{gathered}
$$
反応速度定数 化学量論となる混合分率

$$
\text { ダムケラー数 }
$$

無反応極限に対する量を表す

瞬間反応極限に対する量を表す

無次元化された量を表す 


\section{2. 実験装置および実験条件}

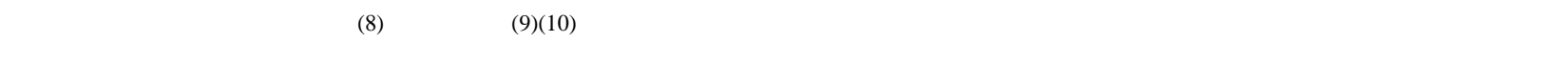
噴流を対象として実験を行った . 本研究で害験に用いた化学反応は次式により表される .

$$
\mathrm{A}+\mathrm{B} \rightarrow \mathrm{R}
$$

ここで, 物質 $\mathrm{A}$ は 1-ナフトール, 物質 $\mathrm{B}$ はジアゾベンゼンスルフォン酸, 物質 $\mathrm{R}$ は赤色のモノアゾ染料である . この化学反応の反応速度定数は $k=12,000 \mathrm{~m}^{3} /(\mathrm{mol} \cdot \mathrm{s})$ とされている ${ }^{(11)}$. 本研究で対象とした二次元噴流の概略図 を図 1 に示す.物質 $\mathrm{B}$ を含む周囲流体中に , 物質 $\mathrm{A}$ を含む溶液を幅 $d=2 \mathrm{~mm}$ のスリットから二次元噴流として流 した．さらに，上記化学反応に影響を与えない染料物質 C (青色, Acid Blue 9) を噴流溶液中に加えた。また，噴 流溶液中に緩衝塩 (炭酸ナトリウムおよび炭酸水素ナトリウム) を加えることで, $\mathrm{pH}$ を一定值 $(\mathrm{pH}=14)$ に保った 。 周囲流および噴流の流量を一定に保つため，溶液はヘッドタンクを通して測定部に供給された . 噴流出口での平 均流速を $U_{\mathrm{J}}=1.29 \mathrm{~m} / \mathrm{s}$ ，周囲流の平均流速を $U_{\mathrm{M}}=0.073 \mathrm{~m} / \mathrm{s}$ とした . また，物質 $\mathrm{A}, \mathrm{B}$ および $\mathrm{C}$ の初期濃度を光

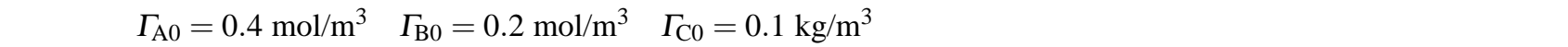
イノルズ数 $R e=\left(U_{\mathrm{J}}-U_{\mathrm{M}}\right) d / v$ は 2,200 である . また , 流れ場の時間スケールの化学反応の代表時間スケールに対 する比であるダムケラ一数は $D a=k\left(\Gamma_{\mathrm{A} 0}+\Gamma_{\mathrm{B} 0}\right) d /\left(U_{\mathrm{J}}-U_{\mathrm{M}}\right)=11.8$ となる . 図 1 のように , 噴流ノズル断面の重心 を座標系の原点とし，流れ方向に $x$ 軸を，噴流の広がり方向に $y$ 軸をとった .

過去に本論文と同樣の流れ場・反応場において速度と濃度の同時計測が行われており，速度と濃度の結合統計量 などの統計量が既報に示されている(9)(10).

\section{3. 濃度測 定方法}

本研究では吸光光度法に基づく光ファイバプローブ(12) と保存スカラー理論 ${ }^{(1)}$ を用いて, 反応に関わる全物質 $\mathrm{A}$, $\mathrm{B}, \mathrm{R}$ および無反応物質 $\mathrm{C}$ の瞬時濃度を同時計測した . 流れ場に含まれる染料物質 $\mathrm{R}, \mathrm{C}$ の瞬時濃度 $\Gamma_{\mathrm{R}}, \Gamma_{\mathrm{C}}$ を光ファ イバプローブにより計測した . 本研究で用いた濃度計測装置により $2,000 \mathrm{~Hz}$ 程度までの濃度の時間変動を精度よ く計測できることが過去に確認されている ${ }^{(13)}$. 光して，保存スカラー理論を流れ場・反応場に適用し， $\Gamma_{\mathrm{R}}, \Gamma_{\mathrm{C}}$ を用 いて反応物質 $\mathrm{A}, \mathrm{B}$ の瞬時濃度 $\Gamma_{\mathrm{A}}, \Gamma_{\mathrm{B}}$ を以下の式より算出した 。

$$
\begin{aligned}
& \Gamma_{\mathrm{A}}=\xi \Gamma_{\mathrm{A} 0}-\Gamma_{\mathrm{R}} \\
& \Gamma_{\mathrm{B}}=(1-\xi) \Gamma_{\mathrm{B} 0}-\Gamma_{\mathrm{R}}
\end{aligned}
$$

ここで, $\xi$ は混合分率であり，無反応物質 $\mathrm{C}$ の瞬時濃度を用いて $\xi \equiv \Gamma_{\mathrm{C}} / \Gamma_{\mathrm{C} 0}$ と定義される．

式 (4), (5)より，反応性物質の質量保存則が以下のように得られる .

$$
\frac{\Gamma_{\mathrm{A}}}{\Gamma_{\mathrm{A} 0}}+\frac{\Gamma_{\mathrm{B}}}{\Gamma_{\mathrm{B} 0}}+\frac{\Gamma_{\mathrm{R}}}{\Gamma_{\mathrm{R} 0}}=1
$$

ここで, $\Gamma_{\mathrm{R} 0}=\Gamma_{\mathrm{A} 0} \Gamma_{\mathrm{B} 0} /\left(\Gamma_{\mathrm{A} 0}+\Gamma_{\mathrm{B} 0}\right)=0.133 \mathrm{~mol} / \mathrm{m}^{3}$ である.

反応速度定数 $k \rightarrow 0$ とする無反応極限 (Frozen limit) における反応性物質の瞬時濃度 $\Gamma_{\alpha}^{0}(\alpha=\mathrm{A}, \mathrm{B}, \mathrm{R})$ が次式よ り求められる ${ }^{(1)}$.

$$
\begin{aligned}
& \Gamma_{\mathrm{A}}^{0} \equiv \lim _{k \rightarrow 0} \Gamma_{\mathrm{A}}=\xi \Gamma_{\mathrm{A} 0} \\
& \Gamma_{\mathrm{B}}^{0} \equiv \lim _{k \rightarrow 0} \Gamma_{\mathrm{B}}=(1-\xi) \Gamma_{\mathrm{B} 0} \\
& \Gamma_{\mathrm{R}}^{0} \equiv \lim _{k \rightarrow 0} \Gamma_{\mathrm{R}}=0
\end{aligned}
$$

また，反応速度定数 $k \rightarrow \infty$ とする瞬間反応極限 (Equilibrium limit) における反応性物質の瞬時濃度 $\Gamma_{\alpha}^{\infty}(\alpha=\mathrm{A}, \mathrm{B}, \mathrm{R})$ 


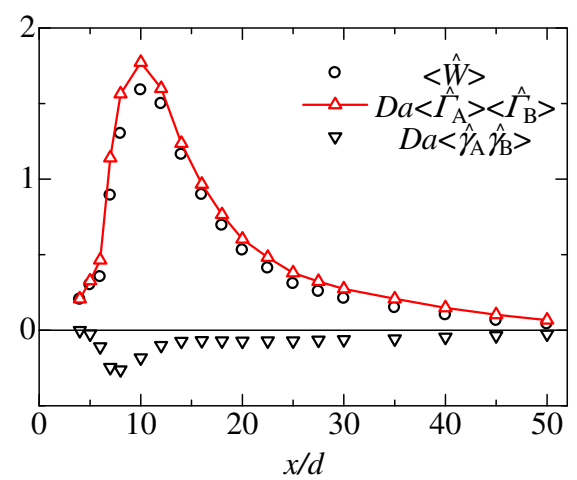

Fig. 2 Axial variation of normalized mean reaction rate on the jet centerline.

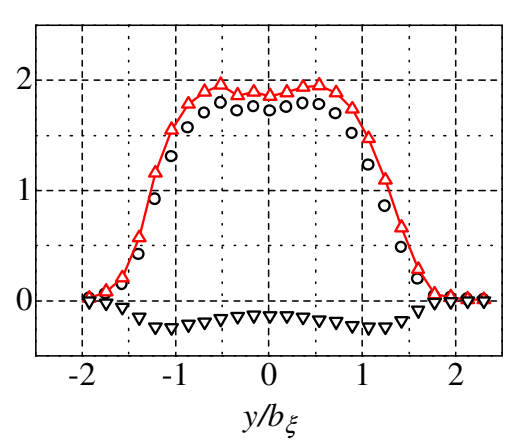

(a) $x / d=10$

$\circ<\hat{W}>\rightarrow-D a<\hat{\Gamma}_{\mathrm{A}}>\left\langle\hat{\Gamma}_{\mathrm{B}}>\quad \nabla \quad D a<\hat{\gamma}_{\mathrm{A}} \hat{\mathrm{H}}_{\mathrm{B}}>\right.$

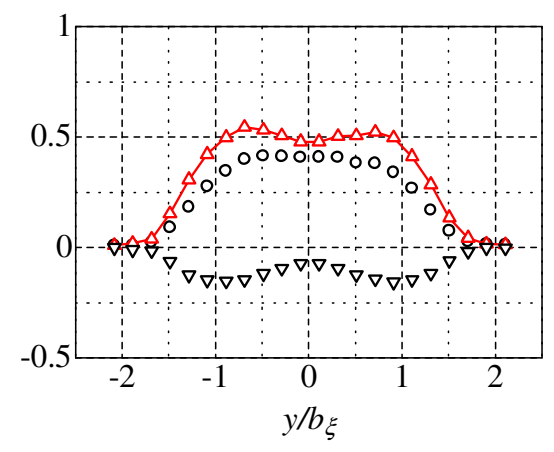

(b) $x / d=20$

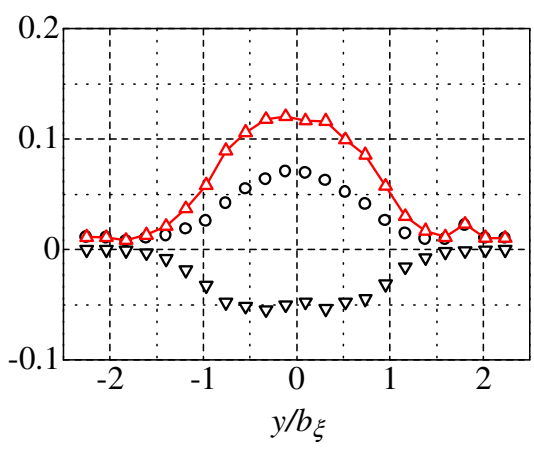

(c) $x / d=40$

Fig. 3 Laterel variation of normalized mean reaction rate.

が次式より求められる(1).

$$
\begin{aligned}
& \Gamma_{\mathrm{A}}^{\infty} \equiv \lim _{k \rightarrow \infty} \Gamma_{\mathrm{A}}=\left(\Gamma_{\mathrm{A} 0}+\Gamma_{\mathrm{B} 0}\right)\left(\xi-\xi_{\mathrm{S}}\right) H\left(\xi-\xi_{\mathrm{S}}\right) \\
& \Gamma_{\mathrm{B}}^{\infty} \equiv \lim _{k \rightarrow \infty} \Gamma_{\mathrm{B}}=\left(\Gamma_{\mathrm{A} 0}+\Gamma_{\mathrm{B} 0}\right)\left(\xi_{\mathrm{S}}-\xi\right) H\left(\xi_{\mathrm{S}}-\xi\right) \\
& \Gamma_{\mathrm{R}}^{\infty} \equiv \lim _{k \rightarrow \infty} \Gamma_{\mathrm{R}}= \begin{cases}\Gamma_{\mathrm{A} 0} \xi & \left(\xi<\xi_{\mathrm{S}}\right) \\
\Gamma_{\mathrm{B} 0}(1-\xi) & \left(\xi \geq \xi_{\mathrm{S}}\right)\end{cases}
\end{aligned}
$$

ここで, $H(z)$ は Heaviside の単位ステッフ関数である .また , $\xi_{\mathrm{S}}$ は混合が化学量論となる混合分率の值であり, 次 式で表される .

$$
\xi_{\mathrm{S}}=\frac{\Gamma_{\mathrm{B} 0}}{\Gamma_{\mathrm{A} 0}+\Gamma_{\mathrm{B} 0}}
$$

本研究の実験条件では, $\xi_{\mathrm{S}}=0.333$ となる.

計測手法についてのより詳細な解説や平均濃度などの統計量ついては既報 ${ }^{(8)(9)(10)}$ に示されている .

\section{4. 実験結果および考察}

\section{1 平均反応速度}

生成物質の無次元濃度 $\hat{\Gamma}_{\mathrm{R}} \equiv \Gamma_{\mathrm{R}} / \Gamma_{\mathrm{R} 0}$ の反応による生成項は $\hat{W}=D a \hat{\Gamma}_{\mathrm{A}} \hat{\Gamma}_{\mathrm{B}}$ により表される .ここで, $\hat{\Gamma}_{\mathrm{A}} \equiv \Gamma_{\mathrm{A}} / \Gamma_{\mathrm{A} 0}$, $\hat{\Gamma}_{\mathrm{B}} \equiv \Gamma_{\mathrm{B}} / \Gamma_{\mathrm{B} 0}$ である．以下では，生成物質の生成項を反応速度と呼ぶ . 式 (2)より，〈ŴW は次のように表すことが できる .

$$
\langle\hat{W}\rangle=D a\left\langle\hat{\Gamma}_{\mathrm{A}}\right\rangle\left\langle\hat{\Gamma}_{\mathrm{B}}\right\rangle+D a\left\langle\hat{\gamma}_{\mathrm{A}} \hat{\gamma}_{\mathrm{B}}\right\rangle
$$




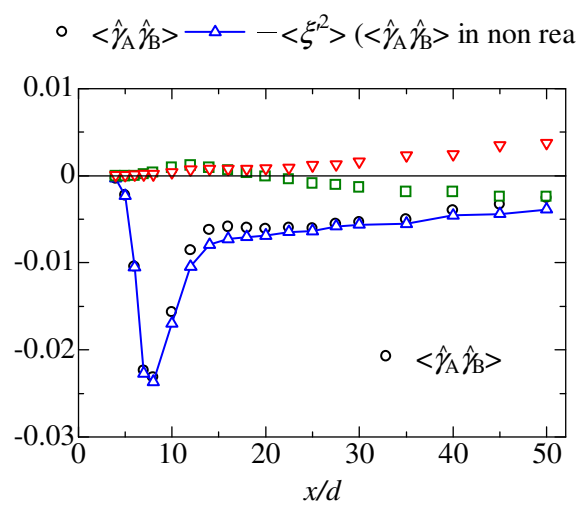

(a) $D a=11.8$

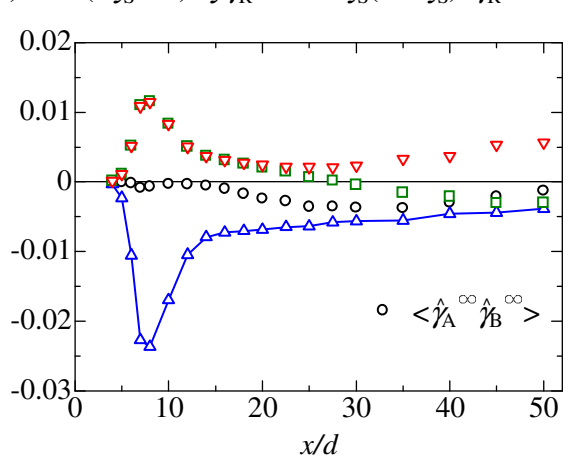

(b) Equilibrium Limit

Fig. 4 Axial variation of normalized concentration correlations on the jet centerline.

ここで, $\hat{\gamma}_{\alpha} \equiv \gamma_{\alpha} / \Gamma_{\alpha 0}(\alpha=\mathrm{A}, \mathrm{B}, \mathrm{R})$ である.

図 2 に平均反応速度 $\langle\hat{W}\rangle$ の噴流中心上における下流方向変化を示す . また , 図 2 には平均濃度積 $D a\left\langle\hat{\Gamma}_{\mathrm{A}}\right\rangle\left\langle\hat{\Gamma}_{\mathrm{B}}\right\rangle$ と 濃度相関項 $D a\left\langle\hat{\gamma}_{\mathrm{A}} \hat{\gamma}_{\mathrm{B}}\right\rangle$ の分布がともに示されている . 噴流中心上において $\langle\hat{W}\rangle$ は $x / d=10$ で極大值をとる . また， 下流に行くにつれて $D a\left\langle\hat{\Gamma}_{\mathrm{A}}\right\rangle\left\langle\hat{\Gamma}_{\mathrm{B}}\right\rangle$ が減少していることから，反応が進行し反応物質の濃度が小さくなることで $\langle\hat{W}\rangle$ は $x / d=10$ より下流に行くにつれて減少することがわかる．濃度相関項 $D a\left\langle\hat{\gamma}_{\mathrm{A}} \hat{\gamma}_{\mathrm{B}}\right\rangle$ は常に負の值をとる．弚して， 噴流中心上の $D a\left\langle\hat{\gamma}_{\mathrm{A}} \hat{\gamma}_{\mathrm{B}}\right\rangle$ は $x / d=8$ で極小值をとり，下流に行くにつれて大きさが小さくなっていく .

図 3 に $\langle\hat{W}\rangle, D a\left\langle\hat{\Gamma}_{\mathrm{A}}\right\rangle\left\langle\hat{\Gamma}_{\mathrm{B}}\right\rangle, D a\left\langle\hat{\gamma}_{\mathrm{A}} \hat{\gamma}_{\mathrm{B}}\right\rangle$ の $x / d=10,20,40$ における $y$ 方向分布を示す . 図中の横軸は平均混合分率 の $y$ 方向分布の半值幅 $b_{\xi}$ で無次元化されている . 図 3(a), (b) より, $x / d=10,20$ では $\left|y / b_{\xi}\right|<0.5$ の噴流中心付

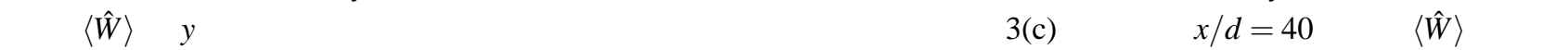
中心で極大值をもつ分布となった . また, $D a\left\langle\hat{\gamma}_{\mathrm{A}} \hat{\gamma}_{\mathrm{B}}\right\rangle$ の $y$ 方向分布は, $x / d=10,20$ では $\left|y / b_{\xi}\right| \approx 1$ で極小值をも つが , $x / d=40$ では噴流中心付近でほぼ一定となることがわかる. 図 2,3 より,$x / d \approx 10$ の噴流中心付近で平均 反応速度が大きくなっており，この領域で反応が活発に進行していることがわかる．また，下流に行くほど濃度相 関項 $D a\left\langle\hat{\gamma}_{\mathrm{A}} \hat{\gamma}_{\mathrm{B}}\right\rangle$ の平均反応速度に対する寄与が大きくなっており，反応速度を求めるために用いる濃度相関項のモ デルの重要性は噴流下流域に行くにつれて高まると考えられる .

\section{$4 \cdot 2$ 反応物質の濃度相関}

4.2.1 濃度相関の化学反応による変化

反応速度は混合度 $I_{\mathrm{S}} \equiv\left\langle\gamma_{\mathrm{A}} \gamma_{\mathrm{B}}\right\rangle /\left(\left\langle\Gamma_{\mathrm{A}}\right\rangle\left\langle\Gamma_{\mathrm{B}}\right\rangle\right)$ を用いて次式のように表すことができる．

$$
\langle W\rangle=k\left\langle\Gamma_{\mathrm{A}}\right\rangle\left\langle\Gamma_{\mathrm{B}}\right\rangle\left(1+I_{\mathrm{S}}\right)
$$

混合度 $I_{\mathrm{S}}$ は二つの反応物質 $\mathrm{A}, \mathrm{B}$ の混合の程度を表す .二つの物質が完全に混合している場合, 濃度変動が 0 とな り $I_{\mathrm{S}}=0$ となる．また，二つの物質が全く混合していない場合， $I_{\mathrm{S}}=-1$ となる.無反応の場合，噴流下流域に行 くにつれて混合が進行し $I_{\mathrm{S}}$ は 0 に近づいていくが, 化学反応による物質の生成によって反応物質 A と B の混合に むらが生じるため，化学反応により $I_{\mathrm{S}}$ の大きさが大きくなる ${ }^{(8)}$. このように混合度は化学反応によって大きく変 化するため, 濃度相関項に対するモデルでは化学反応による影響を考慮することが重要となる . 以下では濃度相 関 $\left\langle\gamma_{\mathrm{A}} \gamma_{\mathrm{B}}\right\rangle$ の化学反心による変化について考察する.

本実験で扱った化学反応よりも一般的な次式で表される化学反応を考える.

$$
\mathrm{A}+n_{\mathrm{B}} \mathrm{B} \rightarrow n_{\mathrm{R}} \mathrm{R}
$$

本実験で扱った化学反応は $n_{\mathrm{B}}=n_{\mathrm{R}}=1$ とした式 (12) に対応している. 式 (12)の化学反応に保存スカラー理論を 
適用することで，反応性物質 A, B, R の瞬時濃度と混合分率の間に次の関係が成り立つことが導かれる .

$$
\begin{aligned}
& \Gamma_{\mathrm{A}}=\xi \Gamma_{\mathrm{A} 0}-\frac{1}{n_{\mathrm{R}}} \Gamma_{\mathrm{R}} \\
& \Gamma_{\mathrm{B}}=(1-\xi) \Gamma_{\mathrm{B} 0}-\frac{n_{\mathrm{B}}}{n_{\mathrm{R}}} \Gamma_{\mathrm{R}}
\end{aligned}
$$

式 (13), (14)より，反応物質 $\mathrm{A}, \mathrm{B}$ の濃度変動 $\gamma_{\mathrm{A}}, \gamma_{\mathrm{B}}$ は混合分率の変動 $\xi^{\prime} \equiv \xi-\langle\xi\rangle$ と生成物質の濃度変動 $\gamma_{\mathrm{R}}$ を用 いて次のように表すことができる

$$
\begin{aligned}
& \gamma_{\mathrm{A}}=\xi^{\prime} \Gamma_{\mathrm{A} 0}-\frac{1}{n_{\mathrm{R}}} \gamma_{\mathrm{R}} \\
& \gamma_{\mathrm{B}}=-\xi^{\prime} \Gamma_{\mathrm{B} 0}-\frac{n_{\mathrm{B}}}{n_{\mathrm{R}}} \gamma_{\mathrm{R}}
\end{aligned}
$$

したがって , 濃度相関 $\left\langle\gamma_{\mathrm{A}} \gamma_{\mathrm{B}}\right\rangle$ は以下のように書ける .

$$
\begin{aligned}
\left\langle\gamma_{\mathrm{A}} \gamma_{\mathrm{B}}\right\rangle & =\left\langle\left(\xi^{\prime} \Gamma_{\mathrm{A} 0}-\frac{1}{n_{\mathrm{R}}} \gamma_{\mathrm{R}}\right)\left(-\xi^{\prime} \Gamma_{\mathrm{B} 0}-\frac{n_{\mathrm{B}}}{n_{\mathrm{R}}} \gamma_{\mathrm{R}}\right)\right\rangle \\
& =-\Gamma_{\mathrm{A} 0} \Gamma_{\mathrm{B} 0}\left\langle\xi^{\prime 2}\right\rangle+\left(\frac{\Gamma_{\mathrm{B} 0}-n_{\mathrm{B}} \Gamma_{\mathrm{A} 0}}{n_{\mathrm{R}}}\right)\left\langle\xi^{\prime} \gamma_{\mathrm{R}}\right\rangle+\frac{n_{\mathrm{B}}}{n_{\mathrm{R}}^{2}}\left\langle\gamma_{\mathrm{R}}^{2}\right\rangle
\end{aligned}
$$

無反応の場合, 生成物質の濃度変動 $\gamma_{\mathrm{R}}$ が 0 となるので, $\left\langle\gamma_{\mathrm{A}} \gamma_{\mathrm{B}}\right\rangle=-\Gamma_{\mathrm{A} 0} \Gamma_{\mathrm{B} 0}\left\langle\xi^{\prime 2}\right\rangle$ である．したがって, 式 (18)の第 一項は無反応の場合の濃度相関を表し，第二項，第三項は反応による濃度相関の変化を表すことがわかる . また , 式 (12) の化学反応において, 化学量論となる反応物質の濃度比は $\Gamma_{\mathrm{A}} / \Gamma_{\mathrm{B}}=1 / n_{\mathrm{B}}$ となる . 反応物質 $\mathrm{A}, \mathrm{B}$ の初期濃 度比がこの関係を満たし， $\Gamma_{\mathrm{A} 0} / \Gamma_{\mathrm{B} 0}=1 / n_{\mathrm{B}}$ となる場合，式 (18)の第二項は常に 0 となる．したがって，この項は 反応物質の初期濃度比と化学量論となる濃度比の違いによって生じる濃度相関の変化と考えられる。

式 (18) を $\Gamma_{\mathrm{A} 0}, \Gamma_{\mathrm{B} 0}$ で無次元化することで，無次元化された濃度相関 $\left\langle\hat{\gamma}_{\mathrm{A}} \hat{\gamma}_{\mathrm{B}}\right\rangle$ が次式のように得られる．

$$
\left\langle\hat{\gamma}_{\mathrm{A}} \hat{\gamma}_{\mathrm{B}}\right\rangle=-\left\langle\xi^{\prime 2}\right\rangle+\left(2 \xi_{\mathrm{S}}-1\right)\left\langle\xi^{\prime} \hat{\gamma}_{\mathrm{R}}\right\rangle+\xi_{\mathrm{S}}\left(1-\xi_{\mathrm{S}}\right)\left\langle\hat{\gamma}_{\mathrm{R}}^{2}\right\rangle
$$

式 (12) の化学反応に対して, 化学量論 $\left(\Gamma_{\mathrm{A}} / \Gamma_{\mathrm{B}}=1 / n_{\mathrm{B}}\right)$ となる混合分率 $\xi_{\mathrm{S}}$ と化学種の質量保存の式 (6) を満たすよ うに定義される $\Gamma_{\mathrm{R} 0}$ は以下のようになる.

$$
\begin{aligned}
\xi_{\mathrm{S}} & =\frac{\Gamma_{\mathrm{B} 0}}{n_{\mathrm{B}} \Gamma_{\mathrm{A} 0}+\Gamma_{\mathrm{B} 0}} \\
\Gamma_{\mathrm{R} 0} & =\frac{n_{\mathrm{R}} \Gamma_{\mathrm{A} 0} \Gamma_{\mathrm{B} 0}}{n_{\mathrm{B}} \Gamma_{\mathrm{A} 0}+\Gamma_{\mathrm{B} 0}}
\end{aligned}
$$

図 4(a) に $\left\langle\hat{\gamma}_{\mathrm{A}} \hat{\gamma}_{\mathrm{B}}\right\rangle$ と式(19) の右辺各項の噴流中心上における分布を示す . また , 图 4(b) に瞬間反応極限 (Equilibrium Limit, $D a \rightarrow \infty)$ の濃度に対して得られた結果を示す . 图中の - $\left\langle\xi^{\prime 2}\right\rangle$ は無反応の場合の濃度相関 $\left\langle\hat{\gamma}_{A}^{0} \hat{\gamma}_{\mathrm{B}}^{0}\right\rangle$ を表して いる . 図 4(a), (b) より，噴流中心上において $\left\langle\hat{\gamma}_{\mathrm{A}} \hat{\gamma}_{\mathrm{B}}\right\rangle$ は化学反応によって大きさが小さなることがわかる . また， $D a=11.8$ の化学反応による $\left\langle\hat{\gamma}_{A} \hat{\gamma}_{B}\right\rangle$ の変化と比較して, 瞬間反応極限での化学反心による $\left\langle\hat{\gamma}_{A} \hat{\gamma}_{B}\right\rangle$ の変化のほうが 大きくなっていることから, 噴流中心上では $D a$ が大きいほど化学反応による $\left\langle\hat{\gamma}_{\mathrm{A}} \hat{\gamma}_{\mathrm{B}}\right\rangle$ の変化 (式 (19) の右辺第二項 と第三項による変化) が大きくなると考えられる . 噴流中心上の噴流上流域 $(x / d<10)$ において式 $(8 \mathrm{~b})$ の $\Gamma_{\mathrm{B}}^{\infty}$ が 常に 0 に近い值となることで, 弚の濃度変動 $\gamma_{\mathrm{B}}^{\infty}$ の大きさも同樣に小さい值となる . 谷のため, 噴流中心上の噴流 上流域では $\left\langle\hat{\gamma}_{\mathrm{A}}^{\infty} \hat{\gamma}_{\mathrm{B}}^{\infty}\right\rangle \approx 0$ となる.

図 5 に $\left\langle\hat{\gamma}_{\mathrm{A}} \hat{\gamma}_{\mathrm{B}}\right\rangle$ と式 (19) の右辺各項の $x / d=10,20,40$ における $y$ 方向分布を示す . また , 図 6 に瞬間反応極限の 濃度に対して得られた結果を示す. $\left\langle\hat{\gamma}_{\mathrm{A}} \hat{\gamma}_{\mathrm{B}}\right\rangle$ の化学反応による変化を詳細に調べるために, 図 $5(\mathrm{a})$ に示した $x / d=10$ における $\left\langle\hat{\gamma}_{\mathrm{A}} \hat{\gamma}_{\mathrm{B}}\right\rangle$ の $y$ 方向分布を図 7 に拡大して示す. 図 5(a) および図 7 より, $x / d=10$ の $\left|y / b_{\xi}\right|>1$ では化学 反応によって $\left\langle\hat{\gamma}_{\mathrm{A}} \hat{\gamma}_{\mathrm{B}}\right\rangle$ の大きさが大きくなることがわかる . また , 図 5 より, $x / d=10$ の $\left|y / b_{\xi}\right|>1$ の位置を除く と, $\left\langle\hat{\gamma}_{\mathrm{A}} \hat{\gamma}_{\mathrm{B}}\right\rangle$ は化学反応によって大きさが小さくなることがわかる.一方 , 図 6 に示した瞬間反応極限での濃度相関 $\left\langle\hat{\gamma}_{\mathrm{A}}^{\infty} \hat{\gamma}_{\mathrm{B}}^{\circ}\right\rangle$ は位置によらず化学反応によって大きさが小さくなった . 図 5(c), 図 6(c) に示した $x / d=40$ の $y / b_{\xi}=1$ 付 近では噴流に含ませた反応物質 $\mathrm{A}$ の多くが反応により消費されており， $\hat{\gamma}_{\mathrm{A}} \approx 0 ， \hat{\gamma}_{\mathrm{A}}^{\infty} \approx 0$ となるため， $\left\langle\hat{\gamma}_{\mathrm{A}} \hat{\gamma}_{\mathrm{B}}\right\rangle \approx 0$ ， $\left\langle\hat{\gamma}_{\mathrm{A}}^{\infty} \hat{\gamma}_{\mathrm{B}}^{\infty}\right\rangle \approx 0$ となる. 
$\circ<\hat{\gamma}_{\mathrm{A}} \hat{\gamma}_{\mathrm{B}}>-\triangle-<\xi^{2}>\left(<\hat{\gamma}_{\mathrm{A}} \hat{\gamma}_{\mathrm{B}}>\right.$ in non reactive case $) \quad \square \quad\left(2 \xi_{\mathrm{S}}-1\right)<\xi^{\prime} \hat{\gamma}_{\mathrm{K}}>\quad \nabla \quad \xi_{\mathrm{S}}\left(1-\xi_{\mathrm{S}}\right)<\hat{\gamma}_{\mathrm{R}}^{2}>$

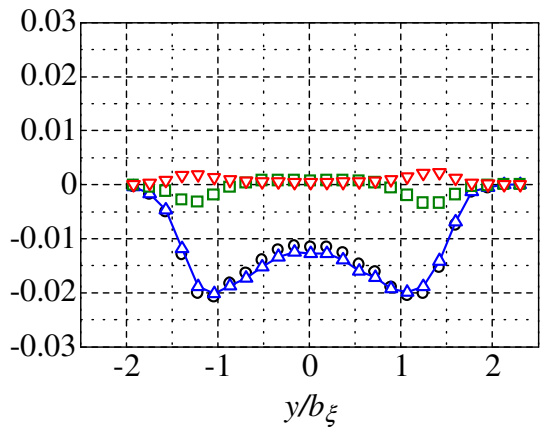

(a) $x / d=10$

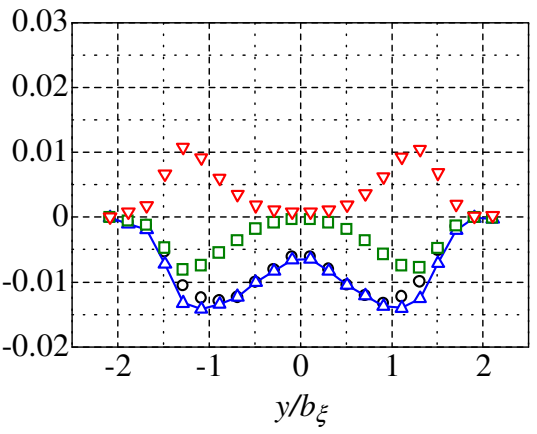

(b) $x / d=20$

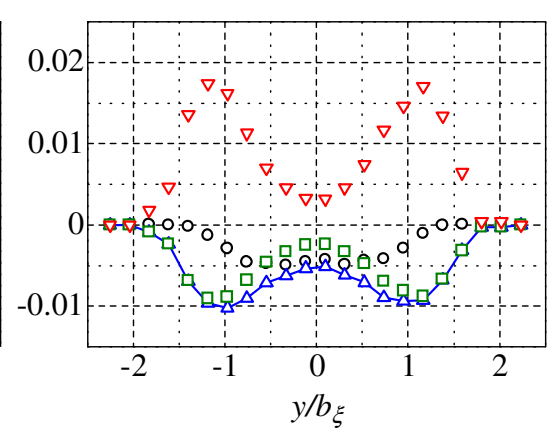

(c) $x / d=40$

Fig. 5 Lateral variation of normalized concentration correlations $(D a=11.8)$.

$\circ<\hat{\gamma}_{\mathrm{A}}^{\infty} \hat{\gamma}_{\mathrm{B}}^{\infty}>-\triangle-<\xi^{2}>\left(<\hat{\gamma}_{\mathrm{A}} \hat{\gamma}_{\mathrm{B}}>\right.$ in non reactive case $) \quad \square \quad\left(2 \xi_{\mathrm{S}}-1\right)<\xi^{\prime} \hat{\gamma}_{\mathrm{R}}^{\infty}>\quad \nabla \quad \xi_{\mathrm{S}}\left(1-\xi_{\mathrm{S}}\right)<\hat{\gamma}_{\mathrm{R}}^{\alpha^{2}}>$

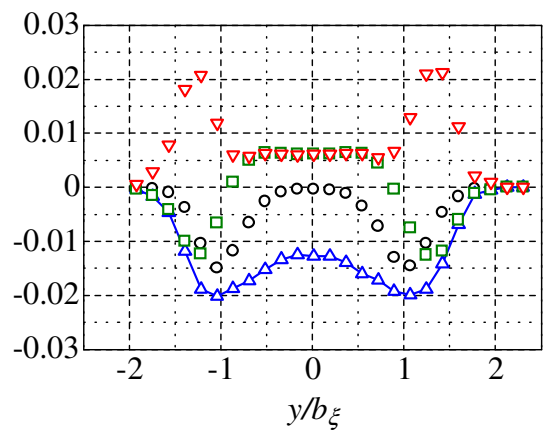

(a) $x / d=10$

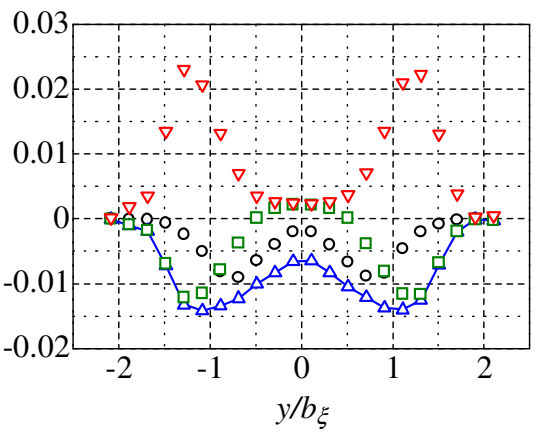

(b) $x / d=20$

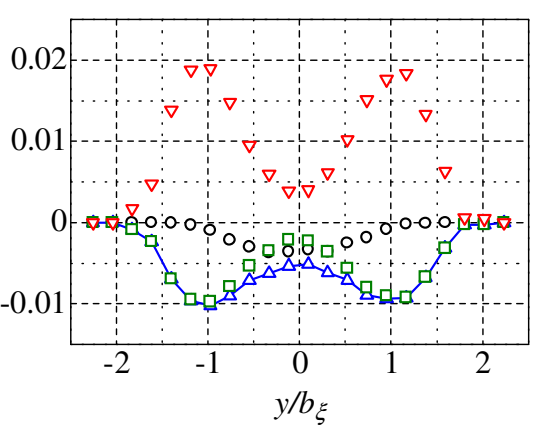

(c) $x / d=40$

Fig. 6 Lateral variation of normalized concentration correlations (Equilibrium limit).

をもつ分布となるが，噴流下流側の $x / d=40$ では噴流中心で極小值をとる分布となった . 以上のように , 噴流上 流域の外縁部では $D a=11.8$ の場合の濃度相関の大きさが反応により大きくなるが , 噴流上流域の外縁部を除いた 位置での $D a=11.8$ の場合の濃度相関や瞬間反応極限での濃度相関は反応が生じない場合と比較して大きさが小さ

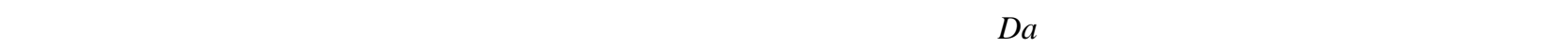

\subsection{2 濃度相関の化学反応による変化に対する位置および $D a$ の影響について}

図 4(a)，図 5 より, $D a=11.8$ の場合 , 式 (19) の第二項 $\left(2 \xi_{\mathrm{S}}-1\right)\left\langle\xi^{\prime} \hat{\gamma}_{\mathrm{R}}\right\rangle$ は噴流上流域の噴流中心付近 (図 4(a) の $x / d<20$, 図 5(a) の $x / d=10$ の $|y / b \xi|<0.7$ ) で正の值, 噴流下流域 (図 4 , 図 5 の $x / d>20$ ) や噴流外縁付近 (図 5(a) $x / d=10$ の $\left.\left|y / b_{\xi}\right|>0.7\right)$ で負の值となることがわかる . また , 図 4(b) , 図 6 に示した瞬間反応極限でも同樣

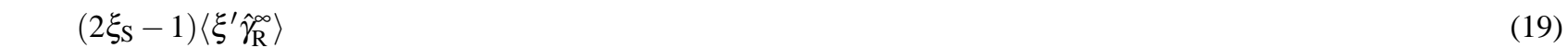
の第二項 $\left(2 \xi_{\mathrm{S}}-1\right)\left\langle\xi^{\prime} \hat{\gamma}_{\mathrm{R}}\right\rangle$ は正・負のどちらにもなりうるが, 第三項 $\xi_{\mathrm{S}}\left(1-\xi_{\mathrm{S}}\right)\left\langle\hat{\gamma}_{\mathrm{R}}^{2}\right\rangle$ は常に正の值となる . したがつ て, 第三項は $\left\langle\hat{\gamma}_{\mathrm{A}} \hat{\gamma}_{\mathrm{B}}\right\rangle$ の大きさを小さ〈する効果をもつ. また , 図 5, 図 6 より, $D a=11.8 て ゙ の \xi_{\mathrm{S}}\left(1-\xi_{\mathrm{S}}\right)\left\langle\hat{\gamma}_{\mathrm{R}}^{2}\right\rangle$ と 比べて瞬間反応極限での $\xi_{\mathrm{S}}\left(1-\xi_{\mathrm{S}}\right)\left\langle\hat{\gamma}_{\mathrm{R}}^{\infty 2}\right\rangle$ のほうが大きくなっており，Daが大きくなるにつれて $\xi_{\mathrm{S}}\left(1-\xi_{\mathrm{S}}\right)\left\langle\hat{\gamma}_{\mathrm{R}}^{2}\right\rangle に$ よる $\left\langle\hat{\gamma}_{\mathrm{A}} \hat{\gamma}_{\mathrm{B}}\right\rangle$ の変化が大きくなると考えられる .

本実験条件においては $\left(2 \xi_{\mathrm{S}}-1\right)<0$ であるため, 上述した $\left(2 \xi_{\mathrm{S}}-1\right)\left\langle\xi^{\prime} \hat{\gamma}_{\mathrm{R}}\right\rangle$ の分布は，噴流上流域の噴流中心付近 で $\left\langle\xi^{\prime} \hat{\gamma}_{R}\right\rangle<0$, 噴流下流域や噴流外縁付近で $\left\langle\xi^{\prime} \hat{\gamma}_{R}\right\rangle>0$ となることに対応している.噴流上流域の噴流中心付近で は反応物質 $\mathrm{A}$ と比較して反応物質 $\mathrm{B}$ が不足しており， $\Gamma_{\mathrm{B}}$ が増加するとき反応速度が大きくなり生成物質濃度 $\Gamma_{\mathrm{R}}$ が 増加 $\left(\gamma_{\mathrm{R}}>0\right)$ する . $\Gamma_{\mathrm{B}}$ の増加は混合分率 $\xi$ の減少 $\left(\xi^{\prime}<0\right)$ と対応しているため，噴流上流域では $\left\langle\xi^{\prime} \gamma_{\mathrm{R}}\right\rangle<0$ となる. 
$\circ<\hat{\gamma}_{\mathrm{A}} \hat{\gamma}_{\mathrm{B}}>--<\xi^{2}>\left(<\hat{\gamma}_{\mathrm{A}} \hat{\gamma}_{\mathrm{B}}>\right.$ in non reactive case $)$

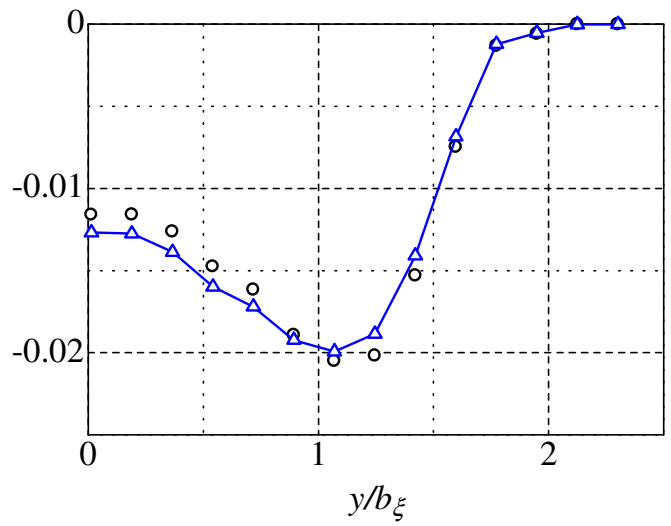

Fig. 7 Lateral variation of normalized concentration correlations at $x / d=10(D a=11.8)$.

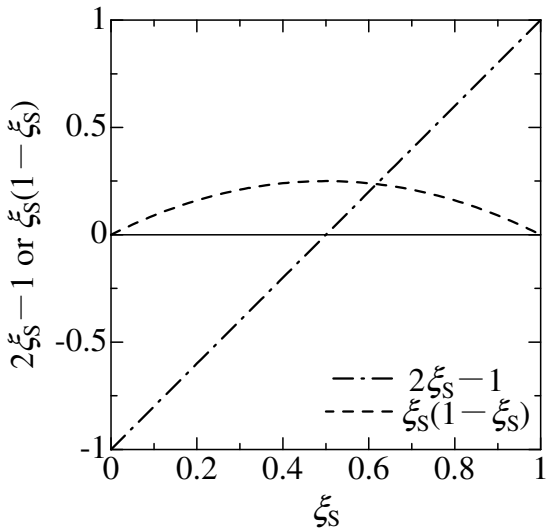

Fig. 8 Changes of $\left(2 \xi_{\mathrm{S}}-1\right)$ and $\xi_{\mathrm{S}}\left(1-\xi_{\mathrm{S}}\right)$ with $\xi_{\mathrm{s}}$.

一方，噴流外縁付近や噴流下流域では反応物質 $\mathrm{B}$ と比較して反応物質 $\mathrm{A}$ が不足しており， $\Gamma_{\mathrm{R}}$ の増加 $\left(\gamma_{\mathrm{R}}>0\right)$ は $\xi$ の増加 $\left(\xi^{\prime}>0\right)$ に関連付けられる . 兴の結果，噴流外縁付近や噴流下流域では $\left\langle\xi^{\prime} \gamma_{\mathrm{R}}\right\rangle>0$ となる . また , $\left(2 \xi_{\mathrm{S}}-1\right)$ の符号は $\xi_{\mathrm{S}}$ によって変化する．したがって，式 (19) の第二項 $\left(2 \xi_{\mathrm{S}}-1\right)\left\langle\xi^{\prime} \hat{\gamma}_{\mathrm{R}}\right\rangle$ の $\left\langle\hat{\gamma}_{\mathrm{A}} \hat{\gamma}_{\mathrm{B}}\right\rangle$ に対する寄与は位置や化 学量論となる混合分率 $\xi_{\mathrm{S}}$ によって大きく変化すると考えられる．また，同樣のことか瞬間反応極限に対しても成 り立つ。

$x / d=10$ の $\left|y / b_{\xi}\right|>1$ (図 5(a), 図 7) では化学反応によって $\left\langle\hat{\gamma}_{\mathrm{A}} \hat{\gamma}_{\mathrm{B}}\right\rangle$ の大きさが大きくなった . これは , 反応物 質の初期濃度比と化学量論となる濃度比の違いによる $\left\langle\hat{\gamma}_{\mathrm{A}} \hat{\mathrm{B}}_{\mathrm{B}}\right\rangle$ の変化を表す式 (19) の第二項 $\left(2 \xi_{\mathrm{S}}-1\right)\left\langle\xi^{\prime} \hat{\gamma}_{\mathrm{R}}\right\rangle$ によ る $\left\langle\hat{\gamma}_{\mathrm{A}} \hat{\gamma}_{\mathrm{B}}\right\rangle$ の変化が第三項 $\xi_{\mathrm{S}}\left(1-\xi_{\mathrm{S}}\right)\left\langle\hat{\gamma}_{\mathrm{R}}^{2}\right\rangle$ にる $\left\langle\hat{\gamma}_{\mathrm{A}} \hat{\gamma}_{\mathrm{B}}\right\rangle$ の変化を上回ることによって生じている. $\xi_{\mathrm{S}}\left(1-\xi_{\mathrm{S}}\right)\left\langle\hat{\gamma}_{\mathrm{R}}^{2}\right\rangle$ は常に正の值となり， $D a=11.8$ の結果 (図 5) と $D a \rightarrow \infty$ に対応する瞬間反応極限の結果 (図 6) との比較から， $\xi_{\mathrm{S}}\left(1-\xi_{\mathrm{S}}\right)\left\langle\hat{\gamma}_{\mathrm{R}}^{2}\right\rangle$ は $D a$ の増加とともに大きくなることがわかる . 光のため, 反応物質の流入条件が $\xi_{\mathrm{S}}=0.5$ を満たし 第二項 $\left(2 \xi_{\mathrm{S}}-1\right)\left\langle\xi^{\prime} \hat{\gamma}_{\mathrm{R}}\right\rangle=0$ となるとき, $\left\langle\hat{\gamma}_{\mathrm{A}} \hat{\gamma}_{\mathrm{B}}\right\rangle$ は無反応極限での值 $\left\langle\hat{\gamma}_{\mathrm{A}}^{0} \hat{\gamma}_{\mathrm{B}}^{0}\right\rangle=-\left\langle\xi^{\prime 2}\right\rangle$ と瞬間反応極限での值 $\left\langle\hat{\gamma}_{\mathrm{A}}^{\infty} \hat{\gamma}_{\mathrm{B}}^{\infty}\right\rangle$ の間に位置し， $\left\langle\hat{\gamma}_{\mathrm{A}}^{0} \hat{\gamma}_{\mathrm{B}}^{0}\right\rangle\left\langle\left\langle\hat{\gamma}_{\mathrm{A}} \hat{\gamma}_{\mathrm{B}}\right\rangle\left\langle\left\langle\hat{\gamma}_{\mathrm{A}}^{\infty} \hat{\gamma}_{\mathrm{B}}^{\infty}\right\rangle\right.\right.$ となる. 光して，この関係を用いてモデルによる $\left\langle\hat{\gamma}_{\mathrm{A}} \hat{\gamma}_{\mathrm{B}}\right\rangle$ の予測値を修 正することが可能となる ${ }^{(6)}$. de Bruyn Kops $ら^{(6)}$ のスカラー混合層で生じる化学反応の DNS おいても， $\xi_{\mathrm{S}} \neq 0.5$ の 場合, 化学反応によって $\left\langle\hat{\gamma}_{\mathrm{A}} \hat{\gamma}_{\mathrm{B}}\right\rangle$ の大きさが大きくなる傾向を示している. 本研究の場合, $\xi_{\mathrm{S}} \neq 0.5$ であったとし ても瞬間反応極限では $\left\langle\hat{\gamma}_{\mathrm{A}} \hat{\gamma}_{\mathrm{B}}\right\rangle$ は化学反応によって大きさが小さくなった . しかし , de Bruyn Kops らの DNS では， $\xi_{\mathrm{S}}=0.032,0.09$ の場合，瞬間反応極限の濃度から求めた $\left\langle\hat{\gamma}_{\mathrm{A}}^{\infty} \hat{\gamma}_{\mathrm{B}}^{\infty}\right\rangle$ も反応によって大きさが大きくなる結果が得ら れている .この理由は式 (19) の第二項 , 第三項の相対的寄与を考えることによってある程度推測することができ る.式(19)の第二項, 第三項の係数である $\left(2 \xi_{\mathrm{S}}-1\right), \xi_{\mathrm{S}}\left(1-\xi_{\mathrm{S}}\right)$ の $\xi_{\mathrm{S}}$ に対する変化を図 8 に示す . 図 8 のように $\xi_{\mathrm{S}}=0$ あるいは 1 に近づくにつれ，式(19)の第二項の影響が第三項と比較して大きくなることがわかる . de Bruyn Kops らの DNS では $\xi_{\mathrm{S}}$ が小さいため式 (19) の第二項による濃度相関の变化が大きくなり，Da よらず濃度相関項 $\left\langle\hat{\gamma}_{\mathrm{A}}^{\infty} \hat{\gamma}_{\mathrm{B}}^{\infty}\right\rangle$ が反応によって大きさが大きくなる結果が得られたと考えられる．一方，本研究において，瞬間反応極限 で $\left\langle\hat{\gamma}_{\mathrm{A}}^{\infty} \hat{\gamma}_{\mathrm{B}}^{\infty}\right\rangle$ が化学反応によって产の大きさが小さくなった理由は，本実験条件では $\xi_{\mathrm{S}}=0.333$ であり，式 (19)の第 三項の係数 $\xi_{\mathrm{S}}\left(1-\xi_{\mathrm{S}}\right)$ の大きさが第二項の係数 $\left(2 \xi_{\mathrm{S}}-1\right)$ と同程度となる (図 8 参照) ことで, 式 (19) の第二項だ けではなく第三項も濃度相関の変化に対して大きく影響するためであると考えられる．

\section{$4 \cdot 3$ 反応物質濃度変動のコスペクトル}

物質 $\alpha$ の濃度変動 $\gamma_{\alpha}$ のフーリエ変換を $\gamma_{\alpha}^{*}$ とし, 物質 $\alpha, \beta$ の濃度変動 $\gamma_{\alpha}, \gamma_{\beta}$ のクロススペクトルを $S_{\alpha \beta} \equiv \overline{\gamma_{\alpha}^{*}} \gamma_{\beta}^{*}$ と定義する .ここで, $\overline{\gamma_{\alpha}^{*}}$ は $\gamma_{\alpha}^{*}$ の複素共役を表す.式(15)，(16) を考慮すると， $\gamma_{\mathrm{A}}, \gamma_{\mathrm{B}}$ のクロススペクトル $S_{\mathrm{AB}}$ は 
$-\hat{C}_{\mathrm{AB}}--S_{\xi \xi}\left(=\hat{C}_{\mathrm{AB}}^{0}\right)-\cdot-\left(2 \xi_{\mathrm{S}}-1\right) \operatorname{Re}\left[\hat{S}_{\xi \mathrm{R}}\right]---\xi_{\mathrm{S}}\left(1-\xi_{\mathrm{S}}\right) \hat{S}_{\mathrm{RR}}$

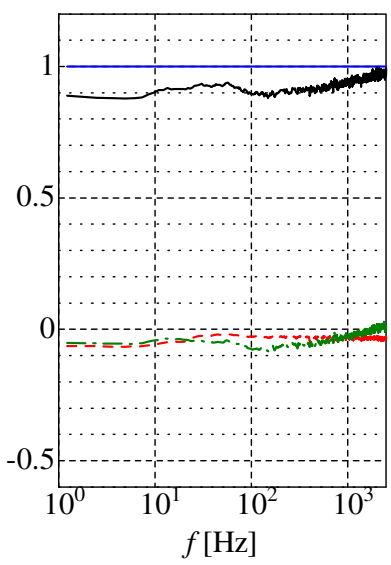

(a) $y / b_{\xi}=0$

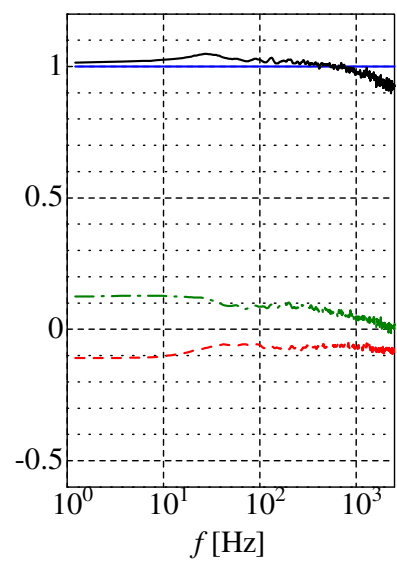

(b) $y / b_{\xi}=1$

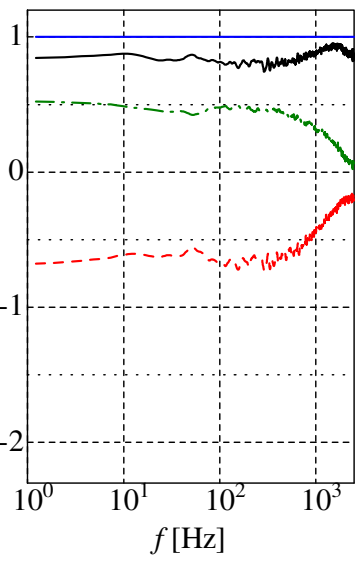

(a) $y / b_{\xi}=0$

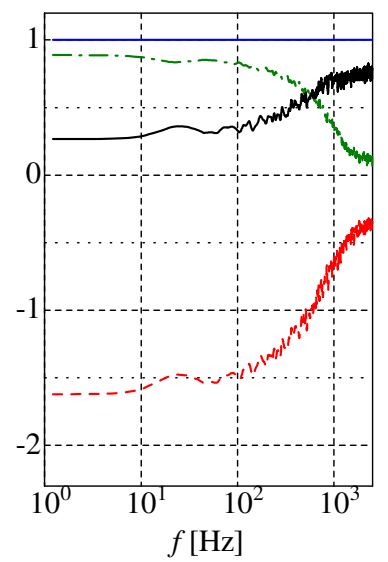

(b) $y / b_{\xi}=1$
Fig. 9 Lateral variation of normalized cospectrum of $\gamma_{\mathrm{A}}$ and $\gamma_{\mathrm{B}}$ at $x / d=10(D a=11.8)$.
Fig. 10 Lateral variation of normalized cospectrum of $\gamma_{\mathrm{A}}$ and $\gamma_{\mathrm{B}}$ at $x / d=40(D a=11.8)$.

$-\hat{C}_{\mathrm{AB}}^{\infty}--S_{\xi \xi}\left(=\hat{C}_{\mathrm{AB}}^{0}\right)-\cdot-\left(2 \xi_{\mathrm{S}}-1\right) \operatorname{Re}\left[\hat{S}_{\xi \mathrm{R}}^{\infty}\right]----\xi_{\mathrm{S}}\left(1-\xi_{\mathrm{S}}\right) \hat{S}_{\mathrm{RR}}^{\infty}$

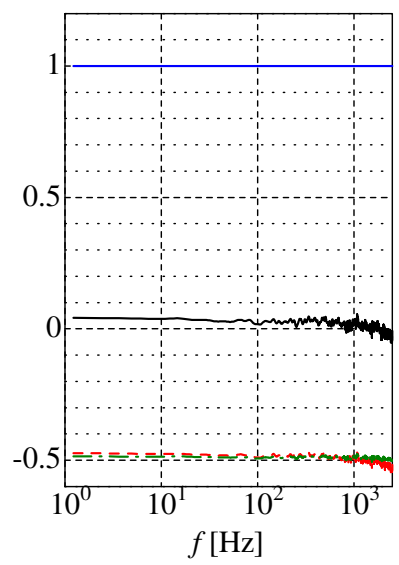

(a) $y / b_{\xi}=0$

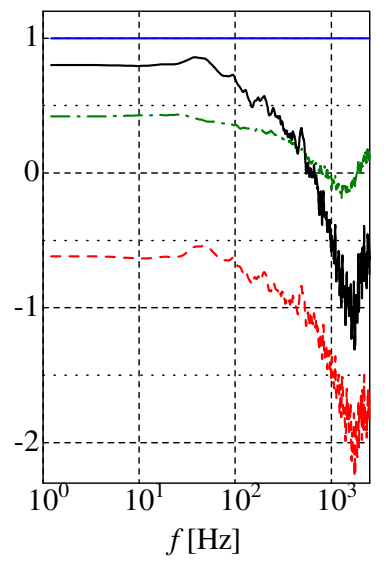

(b) $y / b_{\xi}=1$

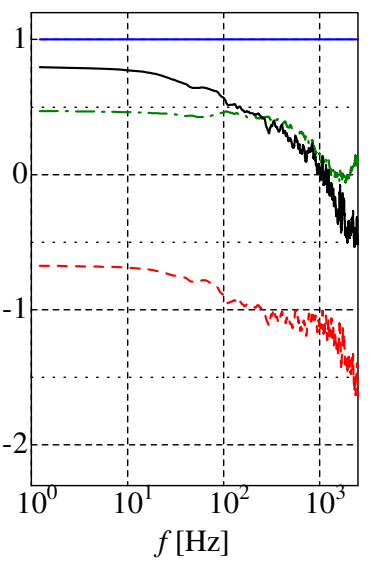

(a) $y / b_{\xi}=0$

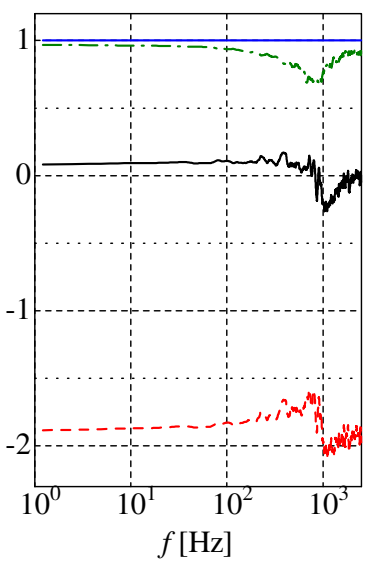

(b) $y / b_{\xi}=1$

Fig. 11 Lateral variation of normalized cospectrum of $\gamma_{\mathrm{A}}^{\infty}$ and $\gamma_{\mathrm{B}}^{\infty}$ at $x / d=10$ (Equilibrium Limit).

Fig. 12 Lateral variation of normalized cospectrum of $\gamma_{\mathrm{A}}^{\infty}$ and $\gamma_{\mathrm{B}}^{\infty}$ at $x / d=40$ (Equilibrium Limit).

以下のように表される .

$$
S_{\mathrm{AB}}=-\Gamma_{\mathrm{A} 0} \Gamma_{\mathrm{B} 0} S_{\xi \xi}+\frac{\Gamma_{\mathrm{B} 0}}{n_{\mathrm{R}}} \overline{S_{\xi \mathrm{R}}}-\frac{n_{\mathrm{B}} \Gamma_{\mathrm{A} 0}}{n_{\mathrm{R}}} S_{\xi \mathrm{R}}+\frac{n_{\mathrm{B}}}{n_{\mathrm{R}}^{2}} S_{\mathrm{RR}}
$$

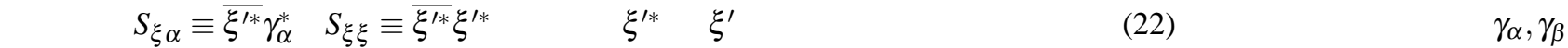
のコスペクトル $C_{\mathrm{AB}} \equiv \operatorname{Re}\left[S_{\mathrm{AB}}\right]$ が以下のように得られる .

$$
C_{\mathrm{AB}}=-\Gamma_{\mathrm{A} 0} \Gamma_{\mathrm{B} 0} S_{\xi \xi}+\frac{\Gamma_{\mathrm{B} 0}-n_{\mathrm{B}} \Gamma_{\mathrm{A} 0}}{n_{\mathrm{R}}} \operatorname{Re}\left[S_{\xi_{\mathrm{R}}}\right]+\frac{n_{\mathrm{B}}}{n_{\mathrm{R}}^{2}} S_{\mathrm{RR}}
$$


ここで, $\operatorname{Re}[*]$ は複素数の実部を表す .さらに, 式 (23) を $\Gamma_{\mathrm{A} 0}, \Gamma_{\mathrm{B} 0}$ で無次元化することで, $\hat{C}_{\mathrm{AB}} \equiv C_{\mathrm{AB}} /\left(\Gamma_{\mathrm{A} 0} \Gamma_{\mathrm{B} 0}\right)$ を $\hat{S}_{\xi \mathrm{R}} \equiv S_{\xi \mathrm{R}} / \Gamma_{\mathrm{R} 0}$ と $\hat{S}_{\mathrm{RR}} \equiv S_{\mathrm{RR}} / \Gamma_{\mathrm{R} 0}^{2}$ を用いて以下のよう表すことができる.

$$
\hat{C}_{\mathrm{AB}}=-S_{\xi \xi}+\left(2 \xi_{\mathrm{S}}-1\right) \operatorname{Re}\left[\hat{S}_{\xi \mathrm{R}}\right]+\xi_{\mathrm{S}}\left(1-\xi_{\mathrm{S}}\right) \hat{S}_{\mathrm{RR}}
$$

式 (19) と同樣に, 式 (24)の第一項は無反応の場合のコスペクトル $\hat{C}_{\mathrm{AB}}^{0}$ を, 第二項は反応物質の初期濃度比と化学 量論となる濃度比の違いによる $\hat{C}_{\mathrm{AB}}$ の変化を，第三項は反応による $\hat{C}_{\mathrm{AB}}$ の変化を示している .

図 9, 10 に光れ光れ $x / d=10,40$ の $y / b_{\xi}=0,1$ における $\hat{C}_{\mathrm{AB}}$ を示す.また，図 11,12 に光れ光れ $x / d=10,40$ の $y / b_{\xi}=0,1$ での瞬間反応極限の濃度から算出したコスペクトル $\hat{C}_{\mathrm{AB}}^{\infty}$ を示す. 各図には無反応の場合のコスペク トル $C_{\mathrm{AB}}^{0}=-S_{\xi \xi}$ で正規化されたコスペクトル $C_{\mathrm{AB}} / C_{\mathrm{AB}}^{0}$ と式 (24)の右辺各項 $\left(-S_{\xi \xi} / C_{\mathrm{AB}}^{0},\left(2 \xi_{\mathrm{S}}-1\right) \operatorname{Re}\left[\hat{S}_{\xi \mathrm{R}}\right] / C_{\mathrm{AB}}^{0}\right.$, $\left.\xi_{\mathrm{S}}\left(1-\xi_{\mathrm{S}}\right) \hat{S}_{\mathrm{RR}} / C_{\mathrm{AB}}^{0}\right)$ が示されている.

図 9(a) より,$x / d=10$ の噴流中心上では，周波数 $f$ によらず $\hat{C}_{\mathrm{AB}}$ は反応により大きさが小さくなることがわか る.また , 図 9(b) に示した $x / d=10$ の $y / b_{\xi}=1$ では $f<600 \mathrm{~Hz}$ で $\hat{C}_{\mathrm{AB}}$ の大きさが反応により大きくなってい る. 図 5(a) に示した $x / d=10$ の噴流外縁付近では, $\hat{C}_{\mathrm{AB}}$ のこの変化により濃度相関 $\left\langle\hat{\gamma}_{\mathrm{A}} \hat{\gamma}_{\mathrm{B}}\right\rangle$ の大きさが化学反応 により大きくなったことがわかる. 図 10(a), (b) に示した $x / d=40$ では周波数が大きくなるにつれ式 (24) の第二 項 , 第三項が 0 に近づき，反応による $\hat{C}_{\mathrm{AB}}$ の変化が小さくなった . また,$x / d=10$ の噴流中心上 (図 9(a)) では， $\left(2 \xi_{\mathrm{S}}-1\right) \operatorname{Re}\left[\hat{S}_{\xi \mathrm{R}}\right] / C_{\mathrm{AB}}^{0}$ と $\xi_{\mathrm{S}}\left(1-\xi_{\mathrm{S}}\right) \hat{S}_{\mathrm{RR}} / C_{\mathrm{AB}}^{0}$ はともに負の值となるが, 噴流中心から外れた位置 (図 9(b)) や噴流下 流域 (図 10) に行くとともに $\left(2 \xi_{\mathrm{S}}-1\right) \operatorname{Re}\left[\hat{S}_{\xi \mathrm{R}}\right] / C_{\mathrm{AB}}^{0}$ は正に , $\xi_{\mathrm{S}}\left(1-\xi_{\mathrm{S}}\right) \hat{S}_{\mathrm{RR}} / C_{\mathrm{AB}}^{0}$ は負に大きくなった .

瞬間反応極限で $\left\langle\hat{\gamma}_{\mathrm{A}}^{\infty} \hat{\gamma}_{\mathrm{B}}^{\infty}\right\rangle \approx 0$ となる $x / d=10$ の噴流中心上 (図 $\left.11(\mathrm{a})\right)$ や $x / d=40$ の $y / b_{\xi}=1$ (図 $\left.12(\mathrm{~b})\right)$ では, $\hat{C}_{\mathrm{AB}}^{\infty}$ は周波数 $f$ によらず 0 に近い值となる .このうち，図 6(a) に示したように $\left(2 \xi_{\mathrm{S}}-1\right)\left\langle\xi^{\prime} \hat{\gamma}_{\mathrm{R}}^{\infty}\right\rangle$ と $\xi_{\mathrm{S}}\left(1-\xi_{\mathrm{S}}\right)\left\langle\hat{\gamma}_{\mathrm{R}}^{\infty 2}\right\rangle$ が同 符号となる $x / d=10$ の噴流中心上では, $\left(2 \xi_{\mathrm{S}}-1\right) \operatorname{Re}\left[\hat{S}_{\xi_{\mathrm{R}}}\right] / \hat{C}_{\mathrm{AB}}^{0} \approx-0.5, \xi_{\mathrm{S}}\left(1-\xi_{\mathrm{S}}\right) \hat{S}_{\mathrm{RR}} / \hat{C}_{\mathrm{AB}}^{0} \approx-0.5$ となることが 図 11(a)よりわかる.逆に, $\left(2 \xi_{\mathrm{S}}-1\right)\left\langle\xi^{\prime} \hat{\gamma}_{\mathrm{R}}^{\infty}\right\rangle$ と $\xi_{\mathrm{S}}\left(1-\xi_{\mathrm{S}}\right)\left\langle\hat{\gamma}_{\mathrm{R}}^{\infty 2}\right\rangle$ の符号が異なる $x / d=40$ の $y / b_{\xi}=1$ (図 6(c) 参照) では, 図 12(b)のように $\left(2 \xi_{\mathrm{S}}-1\right) \operatorname{Re}\left[\hat{S}_{\xi \mathrm{R}}\right] / \hat{C}_{\mathrm{AB}}^{0} \approx 1, \xi_{\mathrm{S}}\left(1-\xi_{\mathrm{S}}\right) \hat{S}_{\mathrm{RR}} / \hat{C}_{\mathrm{AB}}^{0} \approx-2$ となる. $\left\langle\hat{\gamma}_{\mathrm{A}}^{\infty} \hat{\gamma}_{\mathrm{B}}^{\infty}\right\rangle \neq 0$ となる $x / d=10$ の $y / b_{\xi}=1$ (図 11(b)) や $x / d=40$ の $y / b_{\xi}=0$ (図 12(a)) の位置では, 高周波数域で $\xi_{\mathrm{S}}\left(1-\xi_{\mathrm{S}}\right)\left\langle\hat{\gamma}_{\mathrm{R}}\right\rangle$ による $\hat{C}_{\mathrm{AB}}^{\infty}$ の 大きな変化が生じている. これらの位置では $f \approx 1,000 \mathrm{~Hz} て ゙\left(2 \xi_{\mathrm{S}}-1\right) \operatorname{Re}\left[\hat{S}_{\xi_{\mathrm{R}}}\right] / \hat{C}_{\mathrm{AB}}^{0} \approx 0$ となっており，高周波数 域の $\hat{C}_{\mathrm{AB}}^{\infty}$ の化学反応による変化は主に式 (24) の第三項によって生じることがわかる．一方， $D a=11.8$ の場合， $x / d=10$ の $y / b_{\xi}=0$ (図 9(a)) や $x / d=40$ (図 10) における $\hat{C}_{\mathrm{AB}}$ の化学反応による变化は, 高周波数域と比較して 低周波数域で大きくなる傾向がみられる .

このように，反応による $\hat{C}_{\mathrm{AB}}$ の変化の性質は位置や反応速度によって大きく変化する．したがって，反応によ る濃度相関項の変化を適切に見積もることが濃度相関項に対するモデルとして重要となると考えられる．

\section{4 反応項に対するモデル}

濃度相関項 $\left\langle\gamma_{\mathrm{A}} \gamma_{\mathrm{B}}\right\rangle$ に対するモデルは Plug Flow Reactor ${ }^{(14)}$ 中で生じる化学反応に対して Toor ${ }^{(15)}$, Patterson ${ }^{(16)}$, Dutta ら ${ }^{(17)}$ などによって提案されている.Plug Flow Reactor 内の流れ場・濃度場は統計的に一次元であるため, Plug Flow Reactor に対して提案された $\left\langle\gamma_{\mathrm{A}} \gamma_{\mathrm{B}}\right\rangle$ に対するモデルを兴のまま噴流などで生じる化学反応に用いることは難 しい . Wang ら ${ }^{(18)}$ は Toor のモデルと Dutta らのモデルを改良し, 多次元の場に適用できるモデルを提案した . こ こでは, Wang らによって改良された Toor と Dutta らのモデルによる濃度相関 $\left\langle\gamma_{\mathrm{A}} \gamma_{\mathrm{B}}\right\rangle$ の予測値を実験值と比較す ることで , これらのモデルの有効性について検証した .

Toor のモデルでは混合度 $I_{\mathrm{S}} \equiv\left\langle\gamma_{\mathrm{A}} \gamma_{\mathrm{B}}\right\rangle /\left(\left\langle\Gamma_{\mathrm{A}}\right\rangle\left\langle\Gamma_{\mathrm{B}}\right\rangle\right)$ が化学反応によって変化せず，無反応の場合の混合度 $I_{\mathrm{S}}^{0}$ に等 しいことを仮定する . これは Toor の仮説と呼ばれる . 式 (7) を用いると $I_{\mathrm{S}}^{0}$ は以下のように表される .

$$
I_{\mathrm{S}}^{0}=\frac{\left\langle\gamma_{\mathrm{A}}^{0} \gamma_{\mathrm{B}}^{0}\right\rangle}{\left\langle\Gamma_{\mathrm{A}}^{0}\right\rangle\left\langle\Gamma_{\mathrm{B}}^{0}\right\rangle}=-\frac{\left\langle\xi^{\prime 2}\right\rangle}{\langle\xi\rangle(1-\langle\xi\rangle)}
$$

したがって,$I_{\mathrm{S}}=I_{\mathrm{S}}^{0}$ を仮定することで，Toor のモデルでの濃度相関 $\left\langle\gamma_{\mathrm{A}} \gamma_{\mathrm{B}}\right\rangle$ が次式のように得られる．

$$
\left\langle\gamma_{\mathrm{A}} \gamma_{\mathrm{B}}\right\rangle=-\frac{\left\langle\xi^{\prime 2}\right\rangle}{\langle\xi\rangle(1-\langle\xi\rangle)}\left\langle\Gamma_{\mathrm{A}}\right\rangle\left\langle\Gamma_{\mathrm{B}}\right\rangle
$$




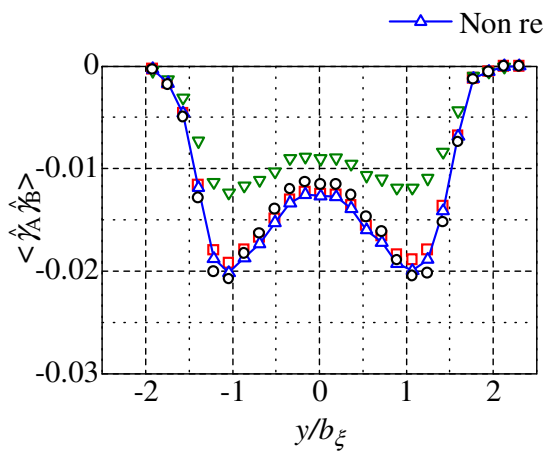

(a) $x / d=10$

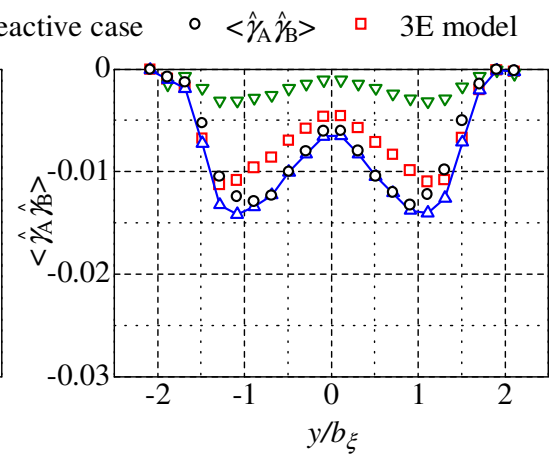

(b) $x / d=20$

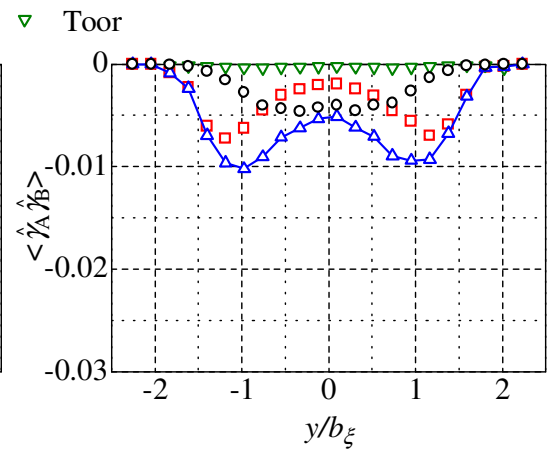

(c) $x / d=40$

Fig. 13 Comparisons of normalized concentration correlations between the measurement results and the models $(D a=11.8)$.

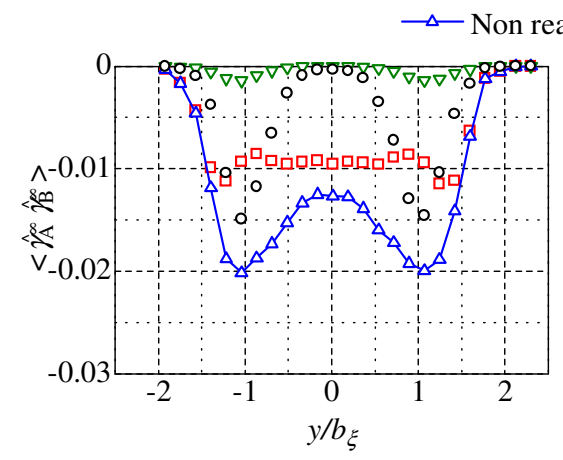

(a) $x / d=10$

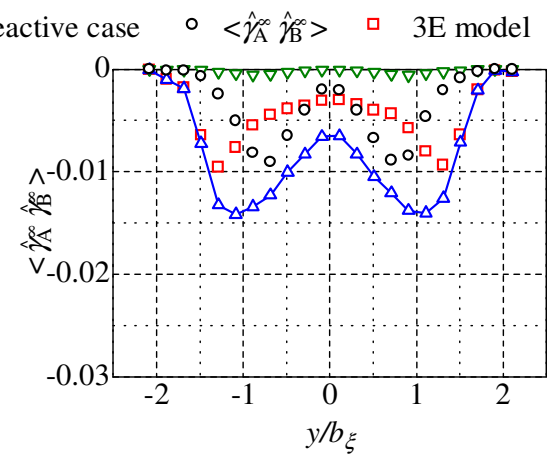

(b) $x / d=20$

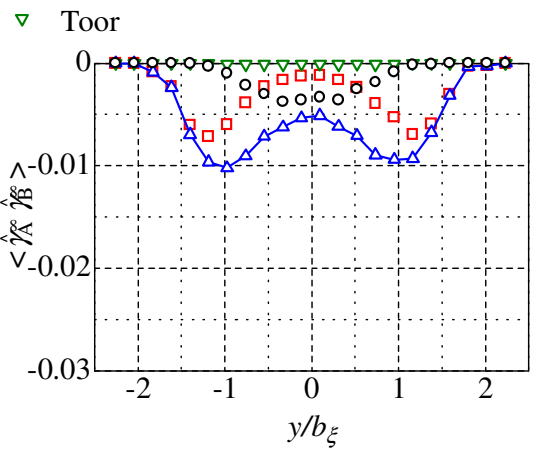

(c) $x / d=40$

Fig. 14 Comparisons of normalized concentration correlations between the measurement results and the models (Equilibrium limit).

Dutta ら ${ }^{(17)}$ のモデルは 3 Environment モデル (3E モデル) と呼ばれる . 3E モデルでは流れ場が，反応物質 $\mathrm{A}$ のみ を含む流体，反応物質 $\mathrm{B}$ のみを含む流体，反応物質 $\mathrm{A}, \mathrm{B}$ が共存する流体の 3 つの流体 (3 Environment) によって 構成されると考える. 本実験で扱った化学反応に対して，3E モデルでの濃度相関 $\left\langle\gamma_{\mathrm{A}} \gamma_{\mathrm{B}}\right\rangle$ は次式により表される．

$$
\begin{aligned}
\left\langle\gamma_{\mathrm{A}} \gamma_{\mathrm{B}}\right\rangle & =I_{\mathrm{S}}^{0}\left(\left\langle\Gamma_{\mathrm{A}}^{0}\right\rangle\left\langle\Gamma_{\mathrm{B}}\right\rangle+\left\langle\Gamma_{\mathrm{A}}\right\rangle\left\langle\Gamma_{\mathrm{B}}^{0}\right\rangle-\left\langle\Gamma_{\mathrm{A}}\right\rangle\left\langle\Gamma_{\mathrm{B}}\right\rangle\right) \\
& =-\frac{\left\langle\xi^{\prime 2}\right\rangle}{\langle\xi\rangle(1-\langle\xi\rangle)}\left(\left\langle\Gamma_{\mathrm{A}}^{0}\right\rangle\left\langle\Gamma_{\mathrm{B}}\right\rangle+\left\langle\Gamma_{\mathrm{A}}\right\rangle\left\langle\Gamma_{\mathrm{B}}^{0}\right\rangle-\left\langle\Gamma_{\mathrm{A}}\right\rangle\left\langle\Gamma_{\mathrm{B}}\right\rangle\right)
\end{aligned}
$$

ここで, $\left\langle\Gamma_{\mathrm{A}}^{0}\right\rangle=\langle\xi\rangle \Gamma_{\mathrm{A} 0},\left\langle\Gamma_{\mathrm{B}}^{0}\right\rangle=(1-\langle\xi\rangle) \Gamma_{\mathrm{B} 0}$ である . したがって, 式 (26), (28) を用いて $\left\langle\gamma_{\mathrm{A}} \gamma_{\mathrm{B}}\right\rangle$ を計算するために は, $\langle\xi\rangle,\left\langle\xi^{\prime 2}\right\rangle$ の輸送方程式を解くなどの手法で $\langle\xi\rangle,\left\langle\xi^{\prime 2}\right\rangle$ を求める必要がある . 以下では, $\langle\xi\rangle,\left\langle\xi^{\prime 2}\right\rangle$ の分布として 実験值を用いることで, 各モデルを用いて得られる化学反応による濃度相関の変化を実験結果と比較する．

図 13 に $x / d=10,20,40$ における $\left\langle\gamma_{\mathrm{A}} \gamma_{\mathrm{B}}\right\rangle$ の $y$ 方向分布を示す. また , 図 14 に $x / d=10,20,40$ における瞬間反応 極限での濃度相関 $\left\langle\gamma_{\mathrm{A}}^{\infty} \gamma_{\mathrm{B}}^{\infty}\right\rangle$ の $y$ 方向分布を示す . 各図中には Toor のモデルと $3 \mathrm{E}$ モデルにより得られる濃度相関お よび無反応の場合の濃度相関 $\left\langle\gamma_{\mathrm{A}}^{0} \gamma_{\mathrm{B}}^{0}\right\rangle$ がともに示されている. 図 13,14 の縦軸は $\Gamma_{\mathrm{A} 0}$ と $\Gamma_{\mathrm{B} 0}$ で, 横軸は平均混合分 率の $y$ 方向分布の半值幅 $b_{\xi}$ で無次元化されている .

図 13,14に示した $\left\langle\hat{\gamma}_{\mathrm{A}} \hat{\gamma}_{\mathrm{B}}\right\rangle,\left\langle\hat{\gamma}_{\mathrm{A}}^{\infty} \hat{\gamma}_{\mathrm{B}}^{\infty}\right\rangle$ を Toor のモデルと比較すると, Toor のモデルでは濃度相関の大きさを実際 よりも小さく見積もることがわかる . 図 13(a) より $3 \mathrm{E}$ モデルにより得られる $x / d=10$ での $\left\langle\hat{\gamma}_{\mathrm{A}} \hat{\gamma}_{\mathrm{B}}\right\rangle$ の分布は実験 値と非常に近いことがわかる . しかし, $3 \mathrm{E}$ モデルで得られた $\left\langle\hat{\gamma}_{\mathrm{A}} \hat{\gamma}_{\mathrm{B}}\right\rangle$ は無反応の場合と比較して常に大きさが小さ 〈なっており,$x / d=10$ の噴流外縁付近での反応により〈 $\left.\hat{\gamma}_{\mathrm{A}} \hat{\gamma}_{\mathrm{B}}\right\rangle$ の大きさが大きくなる変化を $3 \mathrm{E}$ モデルにより捉 えることができていない，反応速度は噴流上流域で大きいため，噴流上流域では化学反応による濃度相関の変化 
が $y$ 方向位置によって異なるという性質を正確に予測できることがモデルには望まれる . 図 13 (b) の $x / d=20$ で は，3E モデルにより得られた $\left\langle\hat{\gamma}_{\mathrm{A}} \hat{\gamma}_{\mathrm{B}}\right\rangle$ は実験值と同樣に噴流中心から外れた位置で極小值をとる分布となった .し かし, さらに下流の $x / d=40$ (図 13(c) , 図 14(c)) では, $3 \mathrm{E}$ モデルにより得られた $\left\langle\hat{\gamma}_{\mathrm{A}} \hat{\gamma}_{\mathrm{B}}\right\rangle や\left\langle\hat{\gamma}_{\mathrm{A}}^{\infty} \hat{\gamma}_{\mathrm{B}}^{\infty}\right\rangle$ は実験值と異 なり，噴流中心から外れた位置で極小值をとる分布となった . また，図 14(a), (b) に示した $x / d=10,20$ において も，3E モデルにより得られた瞬間反応極限での $\left\langle\hat{\gamma}_{\mathrm{A}}^{\infty} \hat{\gamma}_{\mathrm{B}}^{\infty}\right\rangle$ と実験值との間には違いがみられる .このように，化学 反応による濃度相関の変化が小さい位置では, $3 \mathrm{E}$ モデルにより実験值に近い值が得られるが，反応による濃度相 関の変化が大きい位置では, $3 \mathrm{E}$ モデルと実験值の差が大きくなった .

以上のように, Toor のモデルや $3 \mathrm{E}$ モデルでは噴流中で生じる化学反応による濃度相関項の変化を正確に見積も ることが難しいことがわかる . Wang ら ${ }^{(18)}$ は Toor のモデルや $3 \mathrm{E}$ モデルの問題点として , これらのモデルが化学 反応による平均濃度こう配の変化を考慮していないことを挙げている. 乥して, Wang ら ${ }^{(18)}$ は平均濃度こう配の変 化による影響を考慮した Toor のモデルや $3 \mathrm{E}$ モデルを考案し, 平均濃度こう配の変化による影響を考慮すること により濃度相関項の予測精度が向上することを示している . 本研究で計測している統計量からは Wang らのモデル を検証することはできないが，本研究においても，Toor のモデルや $3 \mathrm{E}$ モデルによる予測値と実験值との不一致は 平均濃度こう配の変化による影響を無視したことによるものである可能性が考えられる．

\section{5. 結言}

二次反応 $\mathrm{A}+\mathrm{B} \rightarrow \mathrm{R}$ を伴う液相二次元噴流中で反応性物質の濃度を同時計測し，平均反応速度と反応物質 $\mathrm{A}$ お よび B の濃度相関について調査した . 光して, 平均反応速度を求めるために用いられている濃度相関項に対する モデルによる予測値を実験值と比較し，モデルの有効性について調べた . 本研究により得られた結論を以下にま とめる .

1. 平均反応速度は噴流上流域である $x / d=10$ の噴流中心付近で大きい值となり，この領域で反応が活発に進行 する．また，噴流上流域では噴流中心付近で平均反応速度がほぼ一定となるが，噴流下流域において平均反 応速度は噴流中心付近て極大值をとる分布となる．

2. 反応物質 $\mathrm{A}, \mathrm{B}$ の濃度相関の $y$ 方向分布 ( $y$ : 噴流広がり方向) は噴流上流域の噴流中心から外れた位置や噴流 下流域の噴流中心で極小值をとり，こうした位置で平均反応速度に対する濃度相関項の寄与が大きくなる．ま た，化学反応が進行することで反応物質のどちらか一方の濃度が 0 に近い值となる位置では，反応物質 $\mathrm{A} ， \mathrm{~B}$ の濃度相関は 0 に近い値となる。

3. 反応物質 $\mathrm{A}, \mathrm{B}$ の濃度相関は, 噴流上流域の噴流外縁付近では化学反応により大きさが大きくなり, 他の位置 では化学反応により光の大きさが小さくなる．また，噴流上流域の噴流外縁付近での濃度相関の変化は，反 応物質 $\mathrm{A}, \mathrm{B}$ の初期濃度比と化学量論となる濃度比との違いによる濃度相関の変化が大きくなることにより生 じる . また , 瞬間反応極限での濃度から求めた濃度相関は位置によらず無反応の場合の濃度相関よりも大き さが小さくなる。

4. 瞬間反応極限での反応物質 $\mathrm{A}, \mathrm{B}$ の濃度変動 $\gamma_{\mathrm{A}}^{\infty}, \gamma_{\mathrm{B}}^{\infty}$ のコスペクトル $C_{\mathrm{AB}}^{\infty}$ は, $\left\langle\gamma_{\mathrm{A}}^{\infty} \gamma_{\mathrm{B}}^{\infty}\right\rangle \approx 0$ となる位置では周波 数によらず $C_{\mathrm{AB}}^{\infty} \approx 0$ となる. また， $\left\langle\gamma_{\mathrm{A}}^{\infty} \gamma_{\mathrm{B}}^{\infty}\right\rangle \neq 0$ となる位置では，化学反応による $C_{\mathrm{AB}}^{\infty}$ の変化は高周波数域で 顕著にみられる.これに対して, $D a=11.8$ の場合， $\hat{C}_{\mathrm{AB}}$ の化学反応による変化は, 高周波数域と比較して低 周波数域で大きくなる . 化学反応による反応物質の濃度相関の変化の性質は位置や化学反応によって大きく 変化する .

5. Toor のモデルは $\left\langle\gamma_{\mathrm{A}} \gamma_{\mathrm{B}}\right\rangle$ の大きさを実験值よりも小さく見積もる . 化学反応による $\left\langle\gamma_{\mathrm{A}} \gamma_{\mathrm{B}}\right\rangle$ の変化が小さい位 置では $3 \mathrm{E}$ モデルにより実験值に近い值が得られるが，化学反応による $\left\langle\gamma_{\mathrm{A}} \gamma_{\mathrm{B}}\right\rangle$ の変化が大きくなるにつれて， $3 \mathrm{E}$ モデルと実験值の差が大きくなる .

謝 辞

本研究の一部は科研費 $(25002531 ， 25289030 ， 25289031 ， 25630052)$ の援助を受けて行われた . 本実験にこ協力 いただいた安原大樹氏 (元名古屋大学) に感謝する．また，共著者の長田は小森悟教授 (京都大学) から有益な 助言を多数頂いた. 記して謝意を表する. 


\section{文献}

(1) Bilger, R. W., Saetran, L. R. and Krishnamoorthy, L. V., "Reaction in a Scalar Mixing Layer", Journal of Fluid Mechanics, Vol. 233 (1991), pp. 211-242.

(2) Brown, R. J and Bilger, R. W., "An Experimental Study of a Reactive Plume in Grid Turbulence”, Journal of Fluid Mechanics, Vol. 312 (1996), pp. 373-407.

(3) Komori, S., Kanzaki, T. and Murakami, Y., "Concentration Correlation in a Turbulent Mixing Layer with Chemical Reactions", Journal of Chemical Engineering of Japan, Vol. 27, No. 6 (1994), pp. 742-748.

(4) Zhdanov, V. and Chorny, A., "Development of Macro-and Micromixing in Confined Flows of Reactive Fluids", International Journal of Heat and Mass Transfer, Vol. 54, No. 15 (2011), pp. 3245-3255.

(5) Chorny, A. and Zhdanov, V., "Turbulent Mixing and Fast Chemical Reaction in the Confined Jet Flow at Large Schmidt Number", Chemical Engineering Science, Vol. 68, No. 1 (2012), pp. 541-554.

(6) de Bruyn Kops, S. M., Riley, J. J. and Kosaly, G., "Direct Numerical Simulation of Reacting Scalar Mixing Layers", Physics of Fluids, Vol. 13, No. 5 (2001), pp. 1450-1465.

(7) Fabregat, A., Pallarès, J., Cuesta, I. and Grau, F. X., "Numerical Simulations of a Second-order Chemical Reaction in a Plane Turbulent Channel Flow", International Journal of Heat and Mass Transfer, Vol. 53, No. 19 (2010), pp. 4248-4263.

(8) 久保貴, 福村佳紀, 酒井康彦, 長田孝二, “液相化学反応を伴う二次元噴流に関する研究”, 日本機械学会論文集 B 編, Vol. 76, No. 761 (2010), pp. 57-65.

(9) 渡邊智昭, 酒井康彦, 安原大樹, 長田孝二, 寺島修, 久保貴, “二次反応を伴う液相二次元噴流における速度と反応性スカラー 量の同時測定”, 日本機械学会論文集 B 編, Vol. 78, No. 788 (2012), pp. 769-782.

(10) 渡邊智昭, 酒井康彦, 長田孝二, 寺島修, “反応性乱流拡散場における速度と濃度の結合統計量”, 日本機械学会論文集 B 編, Vol. 78, No. 788 (2012), pp. 783-793.

(11) Bourne, J. R., Hilber, C. and Tovstiga, G., "Kinetics of the Azo Coupling Reactions between 1-naphthol and Diazotised Sulphanilic Acid", Chemical Engineering Communmications, Vol. 37 (1985), pp. 293-314.

(12) 酒井康彦, 中村育雄, 角田博之, 櫛田武広, “吸光スペクトル法によるファイバ型多成分変動濃度計の開発に関する研究”, 日 本機械学会論文集 B 編, Vol. 56, No. 522 (1990), pp. 518-522.

(13) Watanabe, T., Sakai, Y., Nagata, K., Terashima, O. and Kubo, T., "Simultaneous Measurements of Reactive Scalar and Velocity in a Planar Liquid Jet with a Second-order Chemical Reaction”, Experiments in Fluids, Vol. 53, No. 5 (2012), pp. 1369-1383.

(14) Hill, J. C., "Homogeneous Turbulent Mixing with Chemical Reaction”, Annual Review of Fluid Mechanics, Vol. 8, No. 1 (1976), pp. $135-161$.

(15) Toor, H. L., "Turbulent Mixing of Two Species with and without Chemical Reactions", Industrial \& Engineering Chemistry Fundamentals, Vol. 8, No. 4 (1969), pp. 655-659.

(16) Patterson, G. K., "Application of Turbulence Fundamentals to Reactor Modelling and Scaleup", Chemical Engineering Communications, Vol. 8 (1981), pp. 25-52.

(17) Dutta, A. and Tarbell, J. M., “Closure Models for Turbulent Reacting Flows”, AIChE Journal, Vol. 35, No. 12 (1989), pp. 20132027.

(18) Wang, D. M. and Tarbell, J. M., "Closure Models for Turbulent Reacting Flows with a Nonhomogeneous Concentration Field", Chemical Engineering Science, Vol. 48, No. 23 (1993), pp. 3907-3920. 